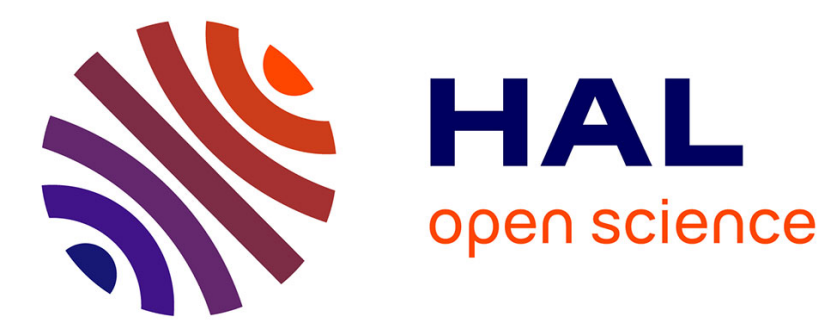

\title{
Bonded repair issues for composites: An investigation approach based on infrared thermography
}

Matthias Barus, Hélène Welemane, Francis Collombet, Marie-Laetitia Pastor, Arthur Cantarel, Laurent Crouzeix, Yves-Henri Grunevald, Valérie Nassiet

\section{- To cite this version:}

Matthias Barus, Hélène Welemane, Francis Collombet, Marie-Laetitia Pastor, Arthur Cantarel, et al.. Bonded repair issues for composites: An investigation approach based on infrared thermography. NDT \& E International, 2017, 85, pp.27-33. 10.1016/j.ndteint.2016.10.003 . hal-01490599

\section{HAL Id: hal-01490599 \\ https://hal.science/hal-01490599}

Submitted on 27 Mar 2017

HAL is a multi-disciplinary open access archive for the deposit and dissemination of scientific research documents, whether they are published or not. The documents may come from teaching and research institutions in France or abroad, or from public or private research centers.
L'archive ouverte pluridisciplinaire HAL, est destinée au dépôt et à la diffusion de documents scientifiques de niveau recherche, publiés ou non, émanant des établissements d'enseignement et de recherche français ou étrangers, des laboratoires publics ou privés. 


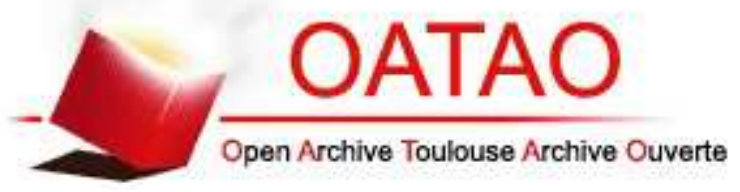

\section{Open Archive Toulouse Archive Ouverte (OATAO)}

OATAO is an open access repository that collects the work of Toulouse researchers and makes it freely available over the web where possible.

This is an author-deposited version published in: http://oatao.univ-toulouse.fr/ Eprints ID: 17511

To link to this article: DOI: $10.1016 /$ j.ndteint.2016.10.003

http://dx.doi.org/10.1016/j.ndteint.2016.10.003

\section{To cite this version:}

Barus, Matthias and Welemane, Hélène and Collombet, Francis and Pastor, Marie-Laetitia and Cantarel, Arthur and Crouzeix, Laurent and Grunevald, Yves-Henri and Nassiet, Valérie Bonded repair issues for composites: An investigation approach based on infrared thermography. NDT \& E International, vol. 85. pp. 27-33. ISSN $\underline{\text { 0963-8695 }}$ 


\title{
Bonded repair issues for composites: An investigation approach based on infrared thermography
}

\author{
M. Barusa,b, H. Welemaneb**, F. Collombeta, M.L. Pastorc, A. CantareJC, L. Crouzeixa, \\ Y.H. Grunevald $<1$, V. Nassietb \\ a Université de Toulouse, UI'3,IUT-ICA, Toulouse, France \\ "Laboratoire Génie de Production (LGP), INP-ENIT, Université de Toulouse, Tarbes, France \\ cInstitut Clément Ader, IUT de Tarbes, Dpt GMP, Tarbes, France \\ d Composites Expertise \& Solutions (CES), Castanet Tolosan, France
}

\section{A R T I C L E I N F O}

\section{Keywords:}

Composite repair

Experimental procedure

Infrared thermography

Heat transfer

Numerical model

\begin{abstract}
A B S T R A C T
An original approach based on active Infrared Thermography (IT) addresses the very challenging issue of the nondestructive analysis of bonded repaired CFRP laminates. Difficulties corne from the weak property contrast between parts of repaired assemblies and thickness of the joint. Strong attention is given here to the control of experimental tests conditions (heat Joad, boundary conditions), which allows to develop a physically consistent numerical mode) of the thermal problem. Comparison between measured and simulated surface temperature fields shows very good agreement regarding temporal and spatial evolutions for composites with different lay-up and offers new solutions for the NonDestructive Testing (NDT) of bonded repaired composites.
\end{abstract}

\section{Introduction}

Design of modern aircraft structures is mainly based on the use of large and noneasily dismantled composite parts. One of the main challenges for aeronautics stands thus in finding relevant and efficient solutions for their structural repair to account for local damages that may be induced in service (bird or vehicle collisions, impacts during plane loading/unloading or maintenance operations, ..). This question is specially difficult to address in the context of CFRP with complex and anisotropie mechanical behavior, but raises for a few years now a growing interest in view of economic issues [1].

The repair purpose is to restore structural properties and strength of the original design. Today, doublers-based solutions using mechanically fastened extra layers of reinforcement are the most conventional techniques for primary structures since they ensure redundancy in structural elements. Yet, it is to note that such process often leads to the creation of new damages during drilling and bolting/riveting phase [2] and, in all cases, leads to extra weight for the repaired structure since the patch dimensions (thickness and surface) may be significant compared to the damage extent. For adhesively bonded repair however, the removed damaged volume is reconstructed by bonding a patch of same material as original on the parent one. This reduces additional weight and tends to preserve the original aerodynamic profile (flush surface), which is of great interest for the repair of external skin panels for instance [3,4]. In case oflaminates, such repair procedure achieves also significatively the Joad transfer within the repaired area, providing a uniform shear dominant stress state and minimizing peel stresses in the adhesive layer $[5,6]$.

For bonded repairs, adhesive bonding of the parent and repair materials requires most attention. The bond strength depends on several factors (type of adhesive, surface aspect, joint design, curing conditions,...) and, above all, is extremely sensitive to the existence of defects (porosity, kiss-bonding, delamination) inside the glue joint. In order to contribute to the reliability assessment of such repair technique, this work intends to provide a nondestructive approach based on active InfraRed Thermography (IRT) able to capture information on bonded joints of repaired primary structures. Precisely, IRT is an optical measurement technique of surface thermal fields usually used for the investigation of structural health (conventional NDT) or damage monitoring in aircraft structures $[7,8]$. In the active configuration, the acquisition of infrared radiation emitted at the part surface and induced by an excitation source (such as ultrasonic waves [9], electromagnetic fields [IO], vibrations [11] and, most often, light source $[12,13])$ allows to identify defects inside materials. It is to note

\footnotetext{
- Corresponding author.

E-mail addresses: matthias.barus@enit.fr (M. Barns),helene.welemane@enit.fr (H.Welemane), francis.collombet@iut-tlse3.fr (F.Collombet), marie.laetitia.pastor@iut-tarbes.fr (M.L. Pastor), arthur.cantarel@iut-tarbes.fr (A. Cantarel), laurent.crouzeix @iut-tlse3.fr (L. Crouzeix),
} yh.grunevald@composites-expertise-solutions.com (Y.H. Grunevald), valerie.nassiet@enit.fr (V. Nassiet). 


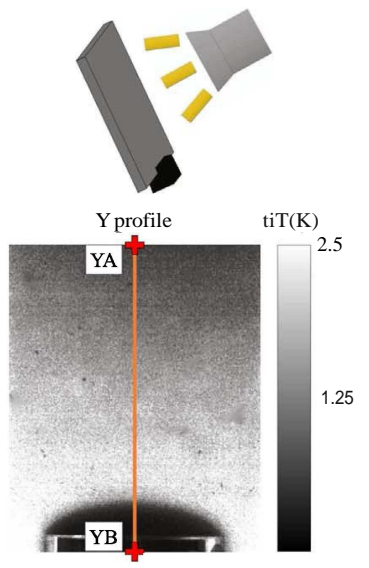

a)

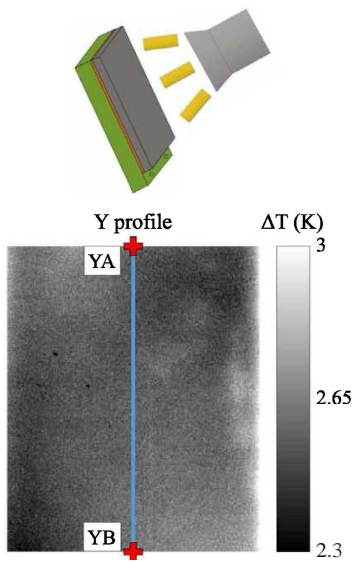

b)

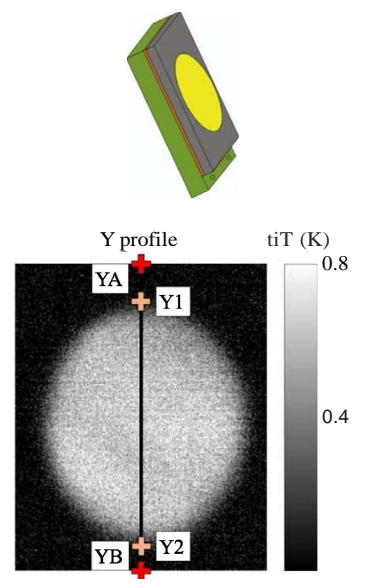

c)

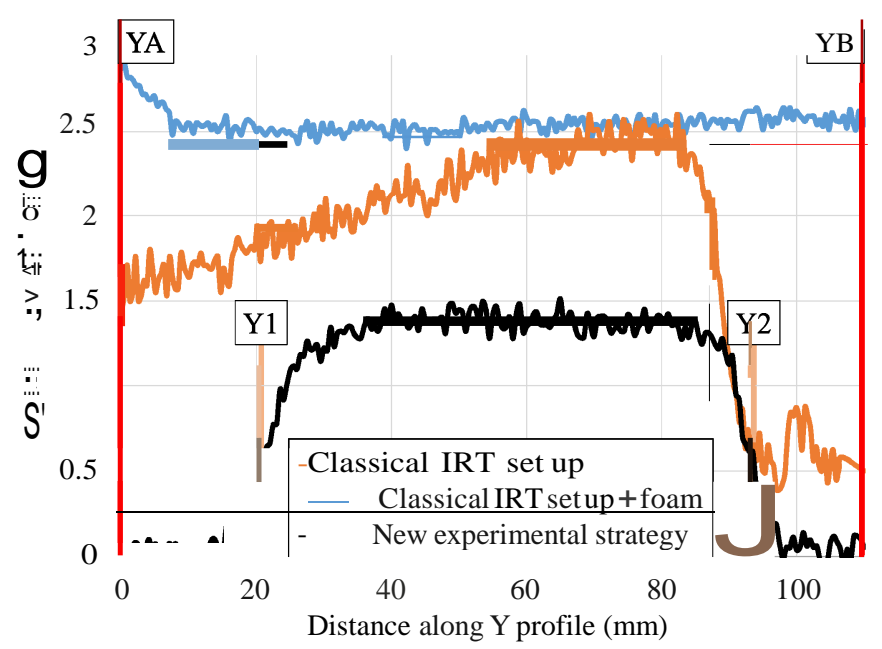

d)

Fig. 1. Surface temperature variation $A T$ for an Jnconel materia!: conventional device (a), insu!ated sample (b) and new procedure (c). Thermal fields (a,b,c) and Ytemperature profiles (d) at $\mathrm{t}=12 \mathrm{~s}$ (step heat Joad begins at $\mathrm{t}=2 \mathrm{~s}$ ). (For interpretation of the references to color in this figure caption, the reader is referred to the web version of this paper.)

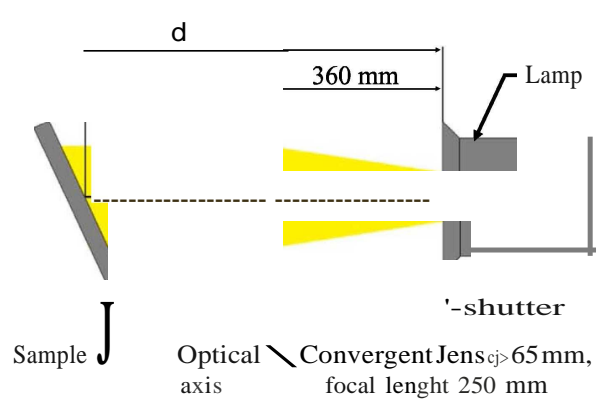

a)

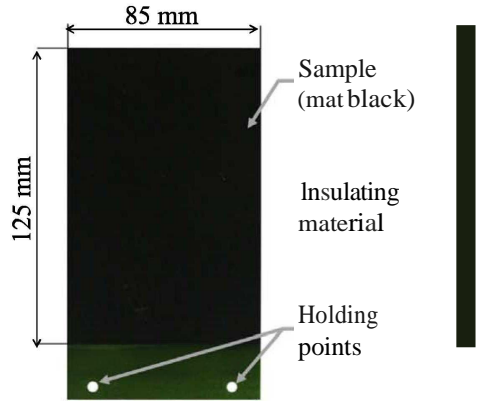

b)

Fig.2. Optical system (a) and sample insulation on back-side (b).

that some post-processing of derived thermal fields may be necessary to reveal and localize more precisely these heterogeneities $[10,14,15]$.

Regarding applications in the repair context, active IRT usually focusses on the detection of artificial defects introduced within the glue joint: Teflon inserts to simulate delaminations and disbondings [1618], grease mould release to represent kiss-bonding or dry fibers to account for porosities [19]. IRT is Jess common in the repair field. The detection capacity of this technique is essentially related to a high property contrast - and thus gap in thermal response - between different parts of the repaired assembly. That is why existing works often deal with optimal configurations such as composite patch pasted on metallic $[16,17]$ or concrete parent structure $[18,20]$, or association of parent and patch made of different composites [21].

The configuration considered in this study corresponds to the industrial context of repaired aircraft primary structures, namely of carbon-epoxy composites (parent and patch) bonded by an epoxy glue. 


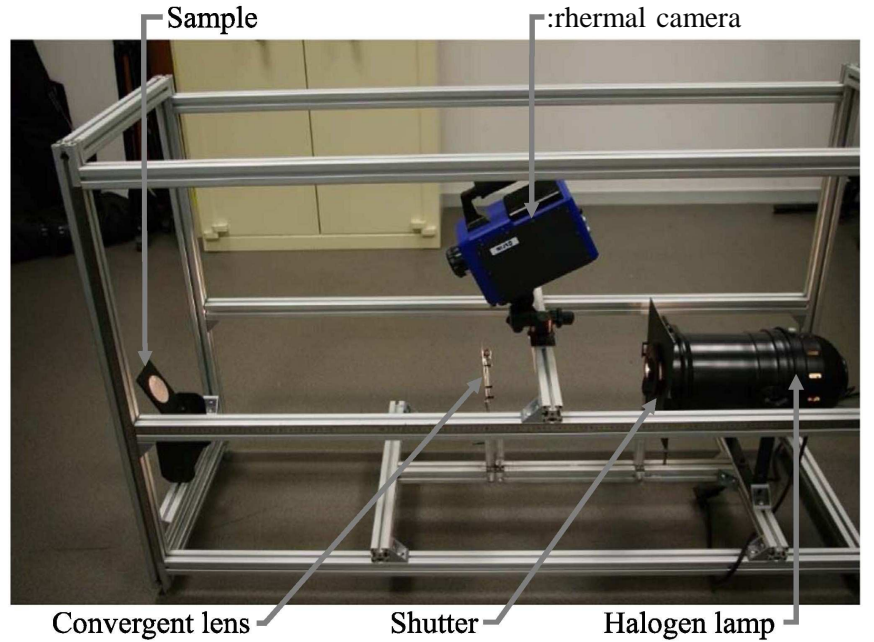

Fig. 3. Specific experimental device.

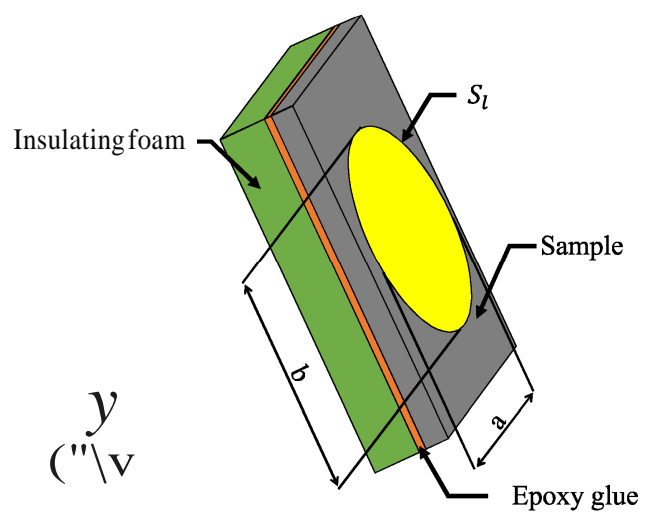

Fig. 4. Schematic representation of the thermal problem.

Table 1

Thermal and physical properties of materials ( $\mathrm{m}$ : measurement, b: bibliography, $\mathrm{f}$ : furnisher, c: calibration); thermal properties measured by Hot Disk TPS 25008; axial (Àa)

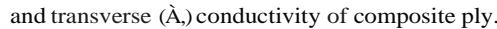

\begin{tabular}{|c|c|c|c|c|c|}
\hline Property & Inconel & $0^{\circ} \mathrm{Ply}$ & Glue & Airex & Adhesive film \\
\hline Density $p\left(\mathrm{~kg} \mathrm{~m}^{-3}\right)$ & $8492 m$ & $1550 \mathrm{~m}$ & $1172=$ & $\mathrm{sa}^{\prime}$ & $1000^{\prime}$ \\
\hline $\begin{array}{c}\text { Specific heat } C p \\
\left(J k g-1 \mathrm{~K}--^{\prime}\right)\end{array}$ & $387 " '$ & $\operatorname{ss} 3=$ & $1317 \mathrm{~m}$ & $113 \mathrm{ob}$ & loooc \\
\hline $\begin{array}{l}\text { Conductivity ̊̀ } \\
(\mathrm{W} \mathrm{m}-1 \mathrm{~K}-1)\end{array}$ & $12=$ & $\begin{array}{l}\text { Àu: } 3 . \text { os! } \\
.<,: \text { o. sic }\end{array}$ & $0.226 \mathrm{~m}$ & O. $033 !$ & O. J2C \\
\hline
\end{tabular}

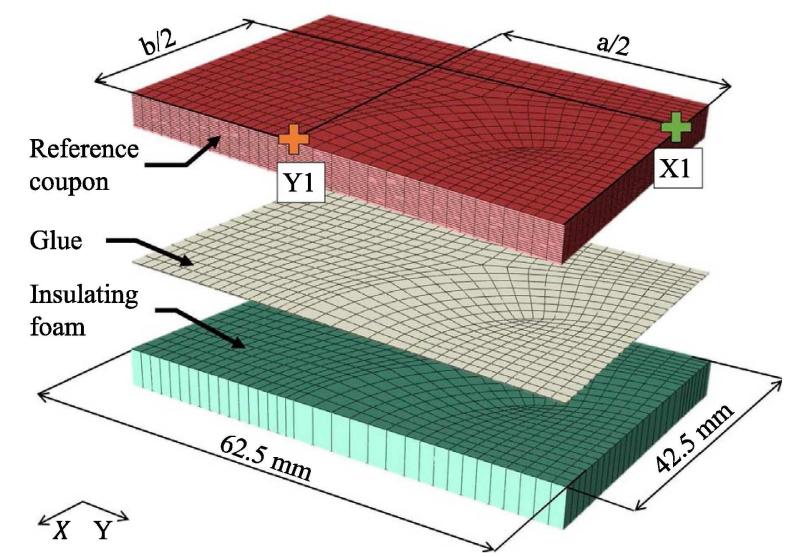

Fig. 5. Constitutive parts of the FE model for the study of virgin materials.
Due to the very slight difference in the thermal behavior of constitutive parts of the repaired assembly, the nondestructive investigation of the bond joint represents a very challenging issue. Contrary to classical NDT investigations, such a question requires here to contrai as much as possible experimental conditions of active IRT tests. In this way, a specific device for heat load has been designed to master the distribution and localization of the heat Joad and the boundary conditions (Section 2). This allows at the same time the definition of a finite element numerical mode! physically consistent with tests conditions (Section 3). From these results, it becomes possible to study the very complex situation of repaired assemblies and to compare measured and simulated temperature fields for different composites lay-up (Section 4).

\section{New experimental strategy}

Current active thermography devices are mostly based on heterogeneous lighting and generally suffer from edge effects [22,23]. Let consider for instance an Inconel plate submitted to a step heat load of $10 \mathrm{~s}$ generated by a halogen lamp (maximum power of $1000 \mathrm{~W}$ ). Inconel sample of $0.9 \mathrm{~mm}$ thickness is painted with black color (so as to consider the emissivity of carbon, $€=0.98$ ) and thermal acquisition is done using a FLIR Titanium SC7000 retrofitted camera (InSb sensors, thermal resolution of $25 \mathrm{mK}$, focal plane of 320x256 pixels) associated with Altair software. Fig. 1a of the surface thermal variation $t ;, . T=T(t)-T_{0}(t=0)$ field and Fig. ld of the related Y temperature profile typically illustrate inconsistencies associated to such a configuration, namely local overheating of the part surface, local cooling on edges and even heat sink at the metallic holding point. As a consequence, simulation models of these tests systematically introduce corrective factors to corroborate experimental measurements [20,24,25]. Accordingly, if these conventional devices remain suitable to capture defects that highly contrast with their integration environment, the challenging issue of composites repair with very weak thermal property contrast basically requires the development of a specific experimental protocol.

Following specifications have been addressed to avoid aforesaid difficulties: (1) the knowledge of the heat flow (location and intensity distribution), (2) the contrai of boundary conditions, (3) the limitation of environmental disturbing effects. Under these conditions, we intend to obtain more refined tests with far Jess disturbance and uncertainty, which furthermore, can be modeled with consistency.

Precisely, the thermal excitation is achieved by means of a halogen lamp delivering initially a nonhomogeneous heat flow. Setting a shutter at its output reduces the generated light beam diameter and a convergent Jens, placed on the optical axis of the lamp, converts as much as possible the divergent light beam into a parallel beam (Fig. 2a). In order to contrai boundary conditions, tested samples are pasted on a reticulated polymer foam (Airex ${ }^{\circledR}$ C70.75) with an epoxy glue (SR1126 and SD8205 hardener) and assemblies are held at the foam bottom (Fig. 2b). Such a foam thermally insulates the back face of the sample and avoids thermal sink at the holding point.

All elements (lamp, shutter, Jens, sample, camera) are inserted into a rigid metallic support that determines precisely the position of the thermal stimulation on the sample (Fig. 3). In view of industrial applications, the reflection configuration has been favoured, for which bath the thermal camera and the heat source stand on the same side of the part. Since the sample surface should be in the camera focal plane, the sample is sloped relative to the light source (forming an angle of $25^{\circ}$ ) and the heat impacted area thus exhibits an elliptical shape whose dimensions are fixed by the Jens diameter and the inclination angle (namely $a=65 \mathrm{~mm}$ wide along minor axis and $b=72 \mathrm{~mm}$ long along major axis).Note that distance between the lamp and the sample along the light axis is equal to $d=760 \mathrm{~mm}$ and that distance between the specimen and the camera $\left(d^{\prime}=670 \mathrm{~mm}\right)$ defines the pixel size, namely $0.4 \times 0.4 \mathrm{~mm}^{2}$. Moreover, so as to limit most disturbing effects of the 


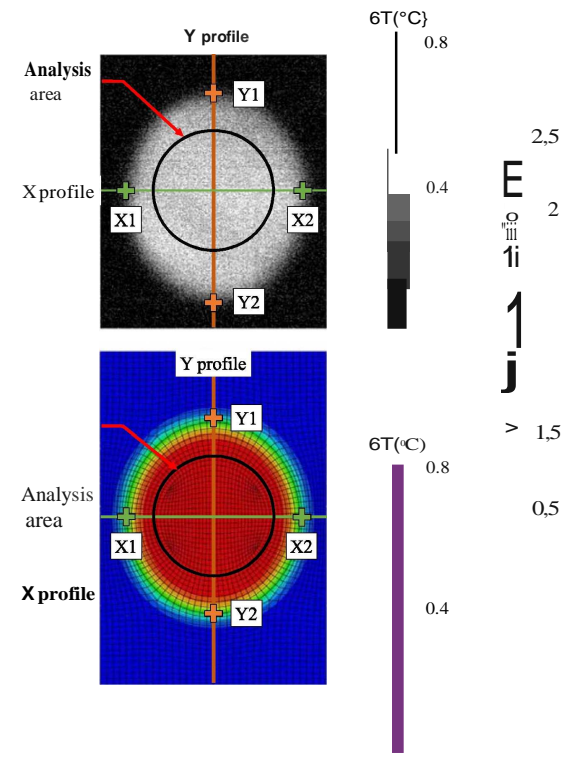
a) Experimental and numerical
b) Time evolution of the average fields at $t=5 \mathrm{~s}$ of $6-T$ over the analysis area

Fig. 6. Surface temperature variation l: $T$ for an Inconel material (points X2 and Y2 are symmetric of Xl and Y1 respectively). (For interpretation of the references to color in this figure caption, the reader is referred to the web version of this paper.)

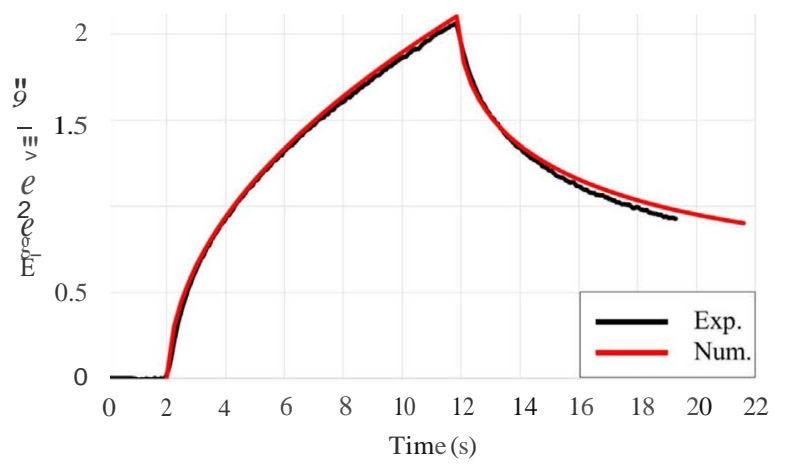

a)

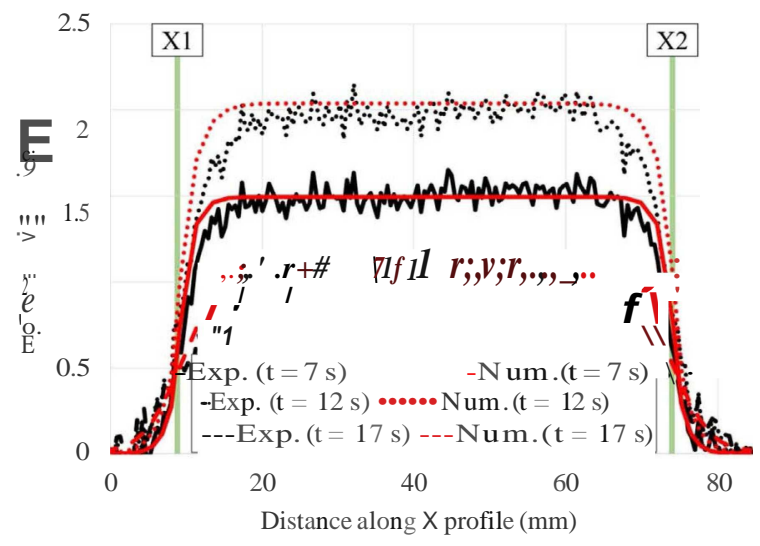

b)

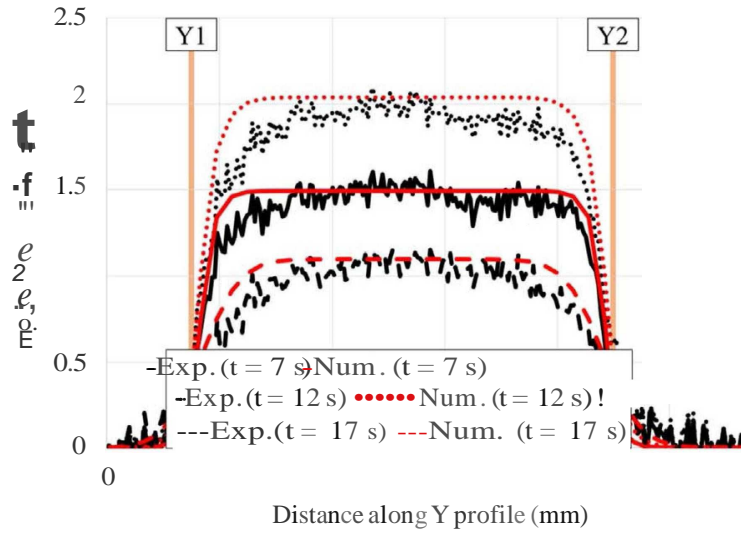

c)

Fig. 7. Surface temperature variation $t ;: T$ for a [0/90/0]6 composite: time evolution of the average of $t ;. T$ over the analysis area (a); X (b) and Y (c) profiles. (For interpretation of the references to color in this figure caption, the reader is referred to the web version of this paper.) 


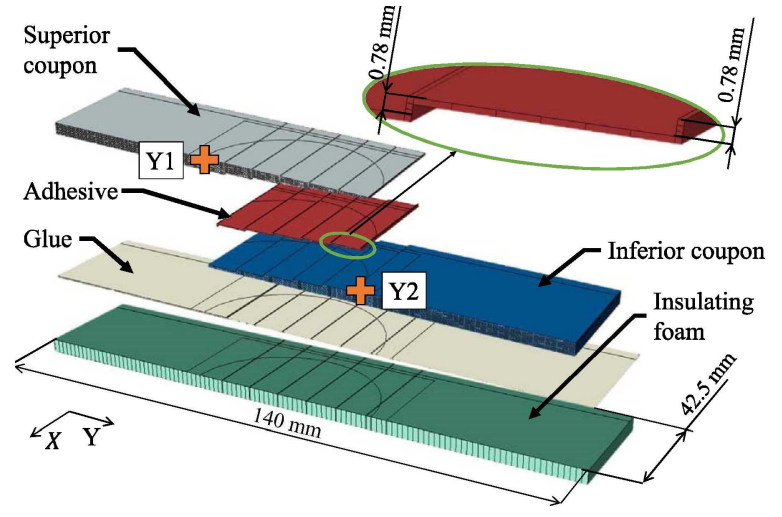

Fig. 8. Constitutive parts of the FE mode! for the study of repaired assemblies.

environment, the bench is entirely covered with a black sheet during measurement.

The different configurations presented in Fig. 1 allow to emphasize the contribution of the new experimental procedure. All these results were obtained for the same material (Inconel), thermal solicitation and equipment (lamp and camera) as the ones considered in Fig. la. Note also that distances $d$ and $d^{\prime}$ are also the same for all figures. Compared to conventional device (diffuse light, metallic holding point, Fig. la and orange line in Fig. ld), the insulation of the sample avoids heat sink at the holding point (close to YB, Fig. lb and blue line in Fig. ld). Yet, the diffuse lighting still generates some edge effects and heterogeneous surface heating (close to YA for instance). The addition of the optical system clearly solves this last difficulty and allows a significant improvement regarding the load distribution (Fig. le and black line in Fig. ld). Even if the shutter and the Jens globally reduce the amount of heat flow received by the sample (and therefore the level of temperature induced on its surface), the new experimental strategy leads to a quasi homogeneous heat Joad intensity on a delimited and defined (elliptical) area on the sample surface. This original approach seems then to offer a proper experimental framework regarding bath the Joad and boundary conditions, that could be easily integrated in terms of numerical modelling.

\section{Modelling strategy and heat flow intensity identification}

The representation of heat transfer inside the material can be modelled using the classical thermodynamics background [26]. Let us consider $V$ the volume of the Representative Volume Element (RVE) of the material, $S$ its outer boundary and $n$ the outward unit normal to $S$. $T=T(x, y, z, t)$ denotes the local temperature of point $M(x, y, z)$ of Vat time $t$. From the thermodynamics principles and Fourier conduction law, one can thus obtain the well-known expression of the local heat equation (without internai sources):

$$
\underset{p C P a T}{a l}-\operatorname{div}(\dot{A} \operatorname{grad} T)=0, \quad \text { V M E V }
$$

with $p$ the material density, $O r$ its specific heat and $\AA$ its thermal conductivity tensor. According to experimental conditions, heat flow on the elliptical impacted area $S_{1}$ (dimensions $a$ and $b$ ) is assumed to be homogeneous (with intensity $<P$ ) and evolves in form of a step of $10 \mathrm{~s}$ (beginning at $\mathrm{t}=2 \mathrm{~s}$, end at $\mathrm{t}=12 \mathrm{~s}$ ). In view of low temperature variations induced within the material, convective and radiative phenomena are neglected (these assumptions were confirmed by a sensibility analysis, see also [25]). Finally, the initial state is defined by the ambient temperature measured within the laboratory. Spatial and temporal boundary conditions for the problem can thus be summarized by (see Fig. 4):

$$
\begin{aligned}
& n \cdot(\operatorname{kgrad} T)=\text { efJ, } \quad \text { V M E S1 } \\
& \{n \cdot(\dot{A} \cdot \operatorname{grad} T)=0, \quad \text { 't } M E S-S 1 \\
& T(x, y, Z, t=0)=T o=T a m b \bullet \quad \mathrm{V} \mathrm{M} \mathrm{E} \mathrm{V}
\end{aligned}
$$

Note that the transient thermal response of materials deduced from Eq. (1) is numerically solved in what follows by finite element method.

In order to fully determine the thermal Joad, it is necessary to quantify the heat flow intensity $<P$ that impacts the sample. The Finite Element Mode!Updating (FEMU) technique has been implemented in this way, using ABAQUS software. At this stage, the sample material in Fig. 4 is the Inconel alloy studied previously (monolithic, isotropie, see properties in Table 1).

Assuming perfect contact, the 3D numerical mode!of the heated assembly includes trough a partition the three constituents (Inconel sample, epoxy glue and Airex insulating foam, Fig. 5). A convergence study has been conducted to ensure the results stability according to the mesh size leading to an average element size of $2 \mathrm{~mm}$ (7290 heat transfer elements DC3D20, mean aspect ratio $b=6.37$ and $0.62 \%$ elements exhibit a $\hat{o}>10$, Fig. 5).

Using FEMU method, heat flow intensity is determined so as to reduce the gap between numerical and experimental average surface temperature over a central area (called analysis area, Fig. 6a). Global response of the model (Fig. 6b) shows its physical consistency with experimental measures and leads to an identified value of efJ $=\left\langle j ; d=500 \mathrm{~W} \mathrm{~m}^{-2}\right.$ with a root mean square error on the average !:T of $0.019 \mathrm{mK}$ which are Jess than the thermal camera measurement noise. Simulation for $\pm 10 \%$ values of $\angle P ; d$ are shown in Fig. $6 \mathrm{~b}$ that illustrate the relevance of such identification. Since simulations are essentially sensitive to the Inconel properties (that were al!identified
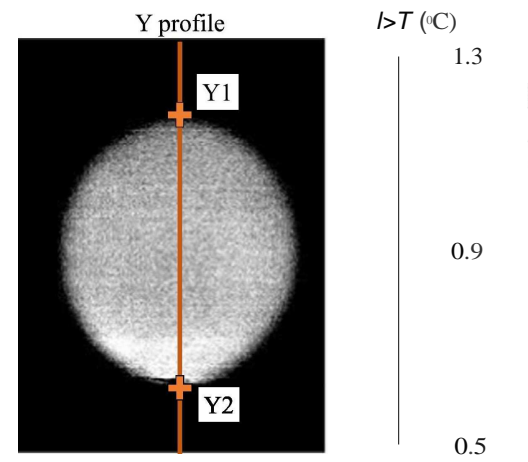

0.5

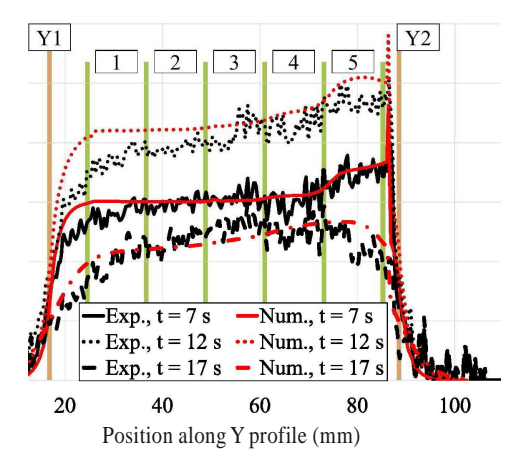

b) Y profiles

Fig. 9. Experimental and numerical surface temperature variation b.T for a [0/90/0]5 composite repaired assembly. Limits of steps are indicated by green lines (respective depths: $3.9 \mathrm{~mm}(1), 3.12 \mathrm{~mm}(2), 2.34 \mathrm{~mm}(3), 1.56 \mathrm{~mm}(4), 0.78 \mathrm{~mm}(5))$. (For interpretation of the references to color in this figure caption, the reader is referred to the web version of this paper.) 


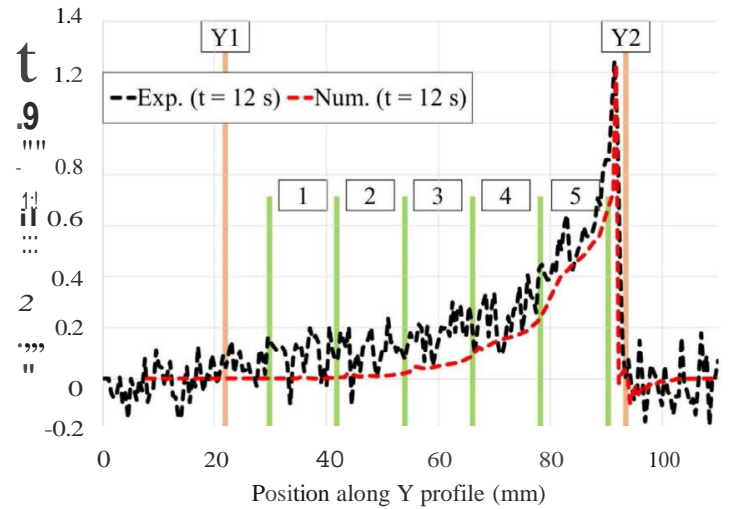

a) $[0 / 90 / 0]_{6}-t=12 \mathrm{~s}$

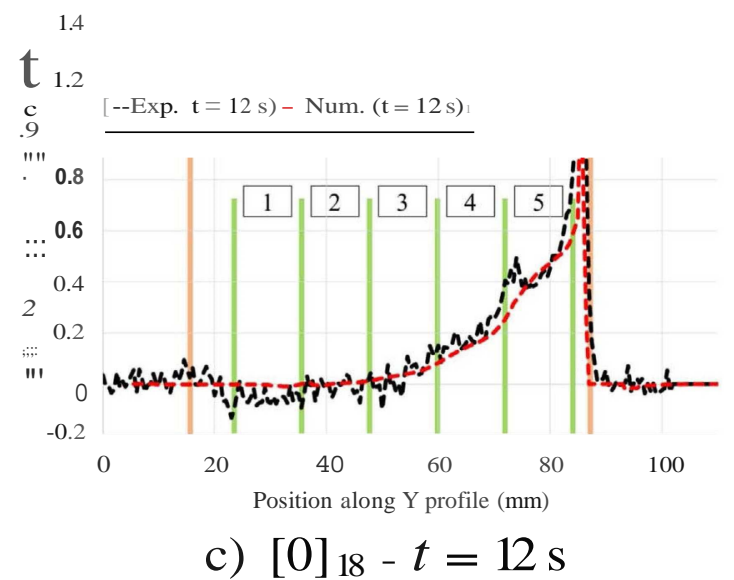

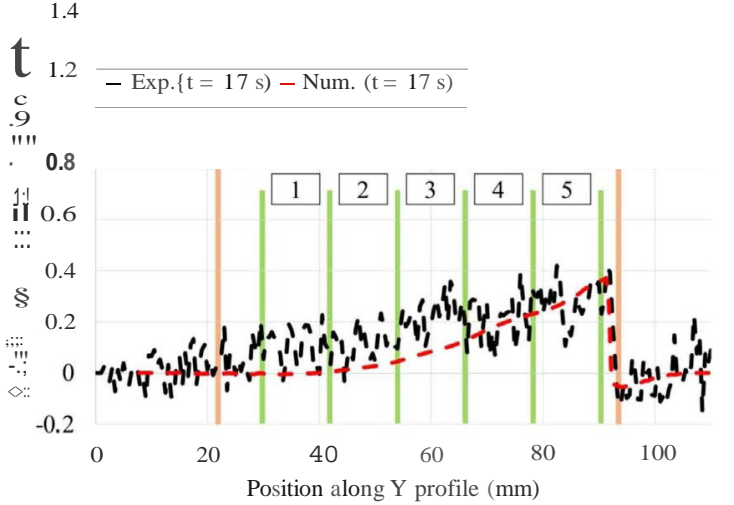

b) $[0 / 90 / 0] 6-t=17 \mathrm{~s}$

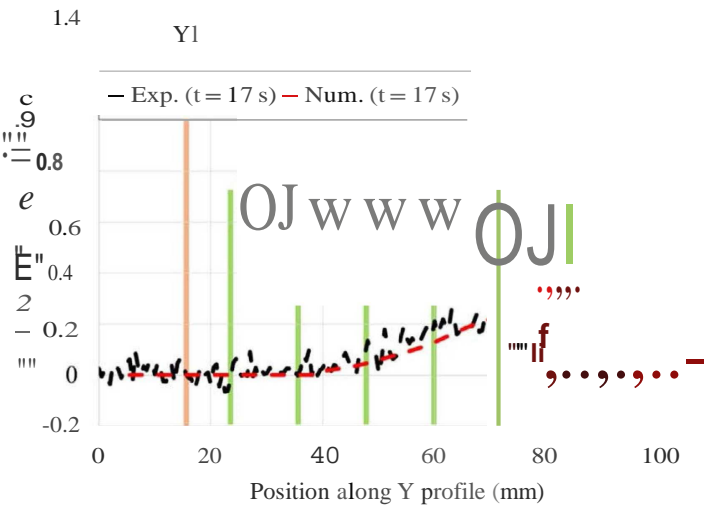

d) $\left[0 \mathrm{Ji}_{8}-t=17 \mathrm{~s}\right.$

Fig. 10. Relative tempera ture $t J .2 T$ along Y profiles for repaired assemblies. Limits of steps are indicated by green lines (respective depths:3.9 mm (1), 3.12 mm (2), 2.34 mm (3), $1.56 \mathrm{~mm} \mathrm{(4),} 0.78 \mathrm{~mm}(5))$. (For interpretation of the references to color in this figure caption, the reader is referred to the web version of this paper.)

experimentally), this gives full confidence in the representation and identification.

Considering the initial issue of this study, the thermal response of a virgin (nonrepaired, monolithic) anisotropie composite laminate under identical conditions and Joad is examined. The sample material in Fig. 4 is now a composite material composed of 18 plies of MIO epoxy resin and T300 carbon fibers with [0/90/0 $]_{6}$ stacking sequence $(4.7 \mathrm{~mm}$ global thickness, monolithic, orthotropic with properties of transversally isotropie ply given in Table 1). The problem geometry is processed in the same manner as previously (Fig. 5) and the modelling of the composite material integrates each ply with related orientation (leading to a total of 13220 elements with $8=8.99$ and $6.08 \%$ elements are such that $/ 5>10$ ). Lacking precision on the transverse conductivity $\dot{A}$, of the $0^{\circ}$ composite ply, this data has been calibrated to match the global material response obtained with heat flow $</ J ; d$ (Fig. 7a). To test the derived representation, one investigates the spatial distribution of surface temperature by means of temperature profiles drawn at different steps (Fig. $7 \mathrm{~b}$ and $7 \mathrm{c}$ ). Results are very satisfactory with a good agreement between numerical and experimental responses during heating and cooling phases, which is particularly noteworthy for such a complex anisotropie context. Note that some slight differences are observed on the edges on profiles of Fig. $7 \mathrm{~b}$ and $7 \mathrm{c}$ (near $\mathrm{Xi}$ and $\mathrm{Yi}$ points) that are due to geometric aberrations of the convergent Jens and that can be reduced using a Jens of a better optical quality. The physical relevance of the mode!should also be underlined through its ability to account for the competition effect between the weak transverse thermal conductivity of composites plies (that induces a rapid evolution of temperature at the beginning of the heat) and their important specific heat (that requires a substantial energy to raise the material temperature), leading to a nonlinear evolution of average $1: !, . T$ (Fig. 7a).

\section{Study of bonded repair assernblies}

Two laminated composite types, namely $[0 / 90 / 0]_{6}$ (orthotropic) and $[0]_{18}$ (transversally isotropie) made of carbon-epoxy composite plies described in Section 3, have been bonded to form repaired assemblies with step lap geometry $\left(0^{\circ}\right.$ ply orientation corresponds in what follows to $Y$ axis). Each step has a length of $12 \mathrm{~mm}$ and a thickness of $0.78 \mathrm{~mm}$, which leads to a total of 5 steps within laminates thickness. Elementary coupons have been machined by water jet to guarantee an optimal surface quality and to reduce delamination [27]. A structural epoxy adhesive film (ST1035) with a thickness of $0.3 \mathrm{~mm}$ is next applied on the connecting surface and polymerized by means of a heating bench. As before, repaired assemblies are finally pasted on the polymer foam with epoxy glue.

Experimental investigations on repaired assemblies have been handled with the new IRT device and for the same step heat Joad as previously with a heating area that covers along $Y$ axis both virgin and repaired areas. Regarding the numerical modelling, a similar strategy as in Section 3 (assumptions, sample material of Fig. 4 being the repaired assembly in that case, elliptical heat Joad with heat flow $</ J ; d$ applied on the superior coupon) has also been implemented. Given the complexity of the present geometry, note that it is better to define each part independently with perfect contact between them, while ensuring coïncidence between the mesh nodes at the contact surfaces (89 383 elements with $8=8.71$ and $12.7 \%$ elements with a $/ 5>10$, Fig. 8 ). Note also that some adhesive film goes up to the surface during the repair 
procedure (as integrated in the numerical model, zoom in Fig. 8). This gives a direct access to the thermal response of the joint (local temperature peak corresponds to the joint flush, see in Fig. 9), whose temporal evolution allows to calibrate missing properties of the adhesive film (Table 1).

Fig. 9 provides surface temperature variations for repaired assemblies. If we examine Y profiles obtained at different times (Fig. 9b), we observe that most important $t: T$ are near point Y2. Indeed, such a zone is strongly affected by the joint (the temperature peak indicates the position of its flush area on the assembly surface and thus the end of repair steps). Since the adhesive film exhibits a weaker thermal effusivity $e=) p J$. $C$ p than composites (Table 1), it acts as a barrier for the heat Joad. More the joint is close to the surface (that is close to Y2), more it avoids the heat diffusion inside the thickness and more the composite temperature rise at this point is important. For this reason, one can already locate the shallowest repair step on $t: T$ profiles for times corresponding to the strong overheating (Fig. $9 \mathrm{~b}$ at $t=7 \mathrm{~s}$ and $\mathrm{t}=12 \mathrm{~s}$ for instance).

Yet, in view of the important heat capacity of thejoint, its insulating character only leads to low amplitude temperature increase for repaired assemblies compared to virgin materials (thermal peak of the joint is about $0.6^{\circ} \mathrm{C}$ more than adjacent composites). In order to improve results interpretation for repair cases, is introduced the socalled relative temperature:

$1172=\mathrm{LiT}($ repaired material $)-\mathrm{t}$..T(virgin material)

where both variations $t: . T$ respectively related to repaired assembly and associated virgin material are obtained under same conditions (Joad and boundary conditions) and correspond to the same time. Such postprocessing removes Jens edge effects and, above all, helps to precisely capture the joint response and repair influence.

The good agreement between experiments and simulation is illustrated on the spatial distribution of $t: T i$ along $Y$ axis for the two composites during both heating and cooling phases (Fig. 10). For areas outside interval [Y1-Y2], no changes in $117 i$ occur since they match the virgin material, that is 18 plies of superior (respectively inferior) coupon for Y1 (resp. Y2) side. Then the current light source (that is $</ J$;a) makes it possible to distinguish the three shallowest repair steps through surface temperature increase on the superior coupon. Comparing the two lay-up shows first that the temperature increase is overall lower for the [0/90/0fo composite. This is due to its more important diffusivity $d \underset{p}{\mathbb{A}} \underset{p}{\text { in }}$ the $X$ direction that leads whatever the depth to a more rapid conduction of overheating towards the sides (along $X$ axis). On the other hand, the more important diffusivity of the $[\mathrm{O}] \mathrm{i}_{8}$ composite in the $Y$ direction increases the heat flow propagation along such direction and induces less pronounced gaps between steps on Y profiles. For both materials, the deepest repair steps (standing at more than $3 \mathrm{~mm}$ depth) are not accessible right now, which is consistent with limits in investigation depths usually encountered by IRT studies with the considered light source [28]. In ail cases, the conduction behavior within the material thickness tends to smooth the response of the joint whatever during the cooling phase.

\section{Conclusion}

The new IRT device proposed in this study allows a clear improvement for experimental mechanics and, specially, for the nondestructive study of bonded repaired composites. Attention was paid to the control of experimental conditions so as to be able to develop a consistent numerical mode of the thermal problem. First results shows a good correlation between measured and simulated temperature fields and allow to highlight the specific infrared response of the bonded joint inside the repair assembly. Further studies are needed now to be conducted to improve the visibility of thejoint, in particular to identify bonding defects. In this way, the present numerical model will allow to investigate the relevance of introducing specific additives inside the bonded joint to exacerbate its thermal response.

\section{References}

[1] Katnam K, Silva LD, Young T. Bonded repair of composite aircraft structures: a review of scientific challenges and opportunities. Progr Aerosp Sei 2013;61:26-42. [2] Liu D, Tang Y, Cong W. A review of mechanical drilling for composite laminates. Compas Struct 2012;94(4):1265-79.

[3] Baker A, Gunnion JA, Wang J. On the certification of bonded repairs to primary composite aircraft components. J Adhes 2015;91(1-2):4-38.

[4] Harman AB, Wang CH. Improved design methods for scarf repairs to highly strained composite aircraft structure. Compas Struct 2006;75(1-4):132-44.

[5] Tomblin J, Salah L, Welch J, Borgman M. Bonded Repair of Aircraft Composite Sandwich Structures. Washington, DC: Office of Aviation Research, Federal Aviation Administration; 2004.

[6] Wang CH, Guunion AJ. Optimum shapes of scarf repairs. Campos Part A: Appl Sei Manuf 2009;40(9):1407-18.

[7] Maldague X. Nondestructive evaluation of materials by infrared thermography. London, United Kingdom: Springer-Verlag; 1993.

[8] Munoz V, Valès B, Perrin M, Pastor ML, Welemane H, Cantarel A, et al. Damage detection in CFRP by coupling acoustic emission and infrared thermography. Campos Part B: Eng 2016;85:68-75.

[9] Spiessberger C, Gleiter A, Busse G.Aerospace applications oflockin-thermography with optical, ultrasonic, and inductive excitation. In: International symposium on NDT in aerospace, Fürth, Germany, 3-5 December, 2008.

[10] Gao B, Woo W, Tian G. Electromagnetic thermography nondestructive evaluation: physics-based modeling and pattern mining. Sei Rep 2016;6:25480.

[11] Wagner D, Ranc N, Bathias C, Paris PC. Fatigue crack initiation detection by an infrared thermography method. Facture Frac! Eng Mater Struct 2009;33:12-21.

[12] Meola C, Boccardi S, Carlomagno GM, Baffa ND, Monaco E, Ricci F. Nondestructive evaluation of carbon fi.ber reinforced composites with infrared thermography and ultrasonics. Compas Struct 2016;134:845-53.

[13] Lizaranzu M, Lario A, Chiminelli A, Amenabar I. Non-destructive testing of composite materials by means of active thermography-based tools. Infrared Phys Technol 2015;71:113-20.

[14] Montanini R, Quattrocchi A, Piccolo SA.Active thermography and post-processing image enhancement for recovering of abraded and paint-covered alphanumeric identification marks. Infrared Phys Technol 2016;78:24-30.

[15] Poudel A, Mitchell KR, Chu TP, Neidigk S, Jacques C. Non-destructive evaluation of composite repairs by using infrared thermography. J Campos Mater 2016:50(3):351-63.

[16] Avdelidis N, Moropoulou A, Marioli ZR. The technology of composite patches and their structural reliability inspection using infrared imaging. Progr Aerosp Sei 2003;39(4):317-28.

[17] Genest M, Martinez M, Mrad N, Renaud G, Fahr A. Pulsed thermography for nondestructive evaluation and damage growth monitoring of bonded repairs. Compas Struct 2009;88(1):112-20.

[18] Tashan J, Al-Mahaidi R. Bond defect detection using PTT IRT in concrete structures strengthened with different CFRP systems. Compos Struct 2014;111:13-9.

[19] Waugh R. Development of infrared techniques for practical defect identification in bonded joints [Ph.D. thesis]. University of Southampton; 2014.

[20] Waugh R, Dulieu-Barton J, Quinn S. Modelling and evaluation of pulsed and pulse phase thermography through application of composite and metallic case studies. NDT \& E nt 2014;66:52-66.

[21] Schroeder J, Ahmed T, Chaudhry B, Shepard S. Non-destructive testing of structural composites and adhesively bonded composite joints :pulsed thermography. Compas Part A: Appl Sei Manuf 2002;33(11): 1511-7.

[22] Amenabar, Mendikute A, L6pez-Arraiza A, Lizaranzu M, Aurrekoetxea J. Comparison and analysis of uon-destructive testing techniques suitable for delamination inspection in wind turbine blades. Compas Part B: Eng 2011;42(5):1298-305.

[23] Mitchell K, Poudel A, Li S, Chu T, Mattingly D. Nondestructive evaluation of composite repairs. In: Proceedings of ASNT 2013 fa!!conference, Las Vegas (USA), 2013, November 4-7.

[24] Aktas A, Gower M, Shaw R, Simpson R, Wright L, Gnaniah S, et al. Nondestructive testing of defects in thick composites by means of pulse and Iock in thermography techniques. In: Proceedings of the 20th International Conference on Composite Materials (ICCM20), Copenhaguen, Deumark, 19-24 July, 2015.

[25] Krishnapillai M, Jones R, Marshall I, Bannisterand M, Rajic N. Thermography as a tool for damage assessment. Compas Struct 2005;67(2):149-55.

[26] Germain P, Nguyen QS, Suquet P. Continuum thermodynamics. J Appl Mech 1983;50:1010-20.

[27] Cénac F, Collombet F, Déléris M, Zitoune R. Abrasive water jet machining of composites. In:Machining composite materials. London (United Kingdom): STE, Wiley; 2009. p. 167-80.

[28] Munoz V, Perrin M, Pastor ML, Welemane H, Cantarel A, Karama M. Application of nondestructive testiug to the detection of aeronautical defects in composite structures. Nonconvent Technol Rev 2013;458-64. 